\title{
Fast Syntax in the Brain: Electrophysiological Evidence from the Rapid Parallel Visual Presentation Paradigm (RPVP)
}

\author{
Yun Wen, Jonathan Mirault, and Jonathan Grainger \\ Aix-Marseille University and National Center for Scientific Research (CNRS), Marseille, France
}

\begin{abstract}
In 2 ERP experiments participants read 4-word sequences presented for $200 \mathrm{~ms}$ (RPVP paradigm) and were required to decide whether the word sequences were grammatical or not. In Experiment 1, the word sequence consisted of either a grammatically correct sentence (e.g., she can sing now) or an ungrammatical scrambled sequence (e.g., sing can now she). A reduced N400 effect was obtained in the grammatically correct sequences compared to the ungrammatical sequences. In Experiment 2, the critical comparison was between 2 types of ungrammatical sequences: transposed-word sequences (e.g., you that read wrong, transposing 2 adjacent central words can form a grammatical sequence) and control sequences (e.g., you that read worry, transposing any 2 adjacent central words still forms an ungrammatical sequence). An N400 reduction was observed in the transposed-word sequences relative to the control sequences. We interpret these N400 effects as evidence that an elementary syntactic representation can be rapidly constructed on the basis of parallel processing of word identities and their parts-of-speech.
\end{abstract}

Keywords: ERPs, fast syntax, grammaticality judgments, rapid parallel visual presentation

Supplemental materials: http://dx.doi.org/10.1037/xlm0000811.supp

Event-related potentials (ERPs) have been extensively used to reveal linguistic operations in the brain (for a review, see Swaab, Ledoux, Camblin, \& Boudewyn, 2012). In the domain of reading comprehension, the majority of studies have focused on two ERP components, namely, the N400 component (a negative deflection peaking around $400 \mathrm{~ms}$ after stimuli onset, discovered by Kutas \& Hillyard, 1980) and the P600 component (a positive deflection peaking around $600 \mathrm{~ms}$ poststimulus, discovered by Osterhout \& Holcomb, 1992). Using the N400 and P600 components as the neural correlates of semantic and syntactic processing respectively, ERP research has substantially advanced our understanding of how skilled readers retrieve syntactic and semantic information encoded in sentences (for reviews, see Friederici \& Weissenborn, 2007; Hagoort, 2009; Kuperberg, 2007; Kutas \& Federmeier, 2011; Kutas, Van Petten, \& Kluender, 2006; Lau, Phillips, \& Poeppel, 2008; Molinaro, Barber, \& Carreiras, 2011; Osterhout, McLaughlin, Kim, Greenwald, \& Inoue, 2004). It is important to

This article was published Online First January 23, 2020.

(D) Yun Wen and Jonathan Mirault, Cognitive Psychology Laboratory, Aix-Marseille University, and National Center for Scientific Research (CNRS), Marseille, France; Jonathan Grainger, Cognitive Psychology Laboratory and Institute for Language Communication and the Brain, AixMarseille University, and National Center of Scientific Research (CNRS).

This research was supported by ERC Grant ADG 742141. We thank Cécile Mahnich, Fanny Broqua, and Charlotte Leflaëc for help with stimuli creation and data collection.

Correspondence concerning this article should be addressed to Yun Wen, Cognitive Psychology Laboratory, Aix-Marseille University, Campus St Charles, 3 Place Victor Hugo, 13331 Marseille, France. E-mail: yun.wen@univ-amu.fr note that the existing ERP findings on reading comprehension are predominantly built on the rapid serial visual presentation (RSVP) paradigm, which uses an incremental word-by-word presentation procedure in order to avoid contamination of ERPs by eye movements. In these RSVP studies, the presentation duration of each word is fixed (e.g., $300 \mathrm{~ms}$ ), and the ERPs are time-locked to the onset of the fixated words, thus providing precise and continuous measures of processing as sentences unfold over time. However, it is obvious that this passive reading involved in the RSVP paradigm is dramatically different from natural reading (for reviews, see Dimigen, Sommer, Hohlfeld, Jacobs, \& Kliegl, 2011; Kornrumpf, Niefind, Sommer, \& Dimigen, 2016; Metzner, von der Malsburg, Vasishth, \& Rösler, 2015). For example, during natural reading the words outside the foveal visual field can be processed as well as the fixated word, and this cannot happen when words are presented in isolation in the RSVP. Because of such methodological limitations, the conventional RSVP studies may not uncover the full cognitive architecture of reading comprehension.

Recent electrophysiological research dedicated to reading has provided complementary approaches to move the field forward. The first promising approach is to measure fixation-related brain potentials (FRPs) rather than ERPs (e.g., Baccino \& Manunta, 2005; Degno et al., 2019; Dimigen, Kliegl, \& Sommer, 2012; Dimigen et al., 2011; Hutzler et al., 2007; Metzner et al., 2015; Nikolaev, Meghanathan, \& van Leeuwen, 2016). In FRP studies, eye movements and the electroencephalogram (EEG) are simultaneously recorded, and the FRPs are time-locked to the first fixation onset of the target stimuli. The most prominent advantage of this approach is that participants can control their eye movements to read experimental stimuli in a way that closely mimics everyday reading. A key finding in FRP studies is that the amplitude of FRPs 
is modulated by parafoveal processing (e.g., Baccino \& Manunta, 2005; Degno et al., 2019; López-Peréz, Dampuré, HernándezCabrera, \& Barber, 2016; Mirault, Yeaton, Broqua, Dufau, Holcomb, \& Grainger, 2019). This finding not only mirrors the parafoveal-on-foveal effect found in the eye-tracking studies (for a review, see Drieghe, 2011), but also unravels neural mechanisms underlying parafoveal processing which cannot be captured by RSVP studies. However, this FRP approach has potential issues (for a systematic review, see Dimigen et al., 2011). For example, the late components of the previously fixated word may temporally overlap with the early components of the currently fixated word, and this overlap may have an unclear impact if experimental stimuli across conditions trigger systematically different fixation durations.

A second complementary approach is to use the RSVP-withflanker paradigm, a modified version of the RSVP paradigm. Barber, Doñamayor, Kutas, and Münte (2010) used this RSVPwith-flanker paradigm for the first time to determine whether semantic congruency of the parafoveal words can modulate the ERP response to the fixated word. In this seminal study, the RSVP was used to present sentences, but critically three words were presented at one go, that is, the currently fixated word at the center, accompanied by two flankers with the previously fixated word on the left and the next word to be fixated on the right. Unknown to participants, the target words were accompanied by right flankers that were either semantically congruent or incongruent with the preceding context, that is, the target word without in Tino could not read well without glasses was presented with either the congruent flanker glasses or the incongruent flanker mice on the right. A reduced N400 was found in the congruent flanker condition compared with the incongruent flanker condition, providing evidence for parafoveal processing at the semantic level. Follow-up studies using the same paradigm observed similar findings of parafoveal processing as evidenced by P2 or N400 effects (Barber, Ben-Zvi, Bentin, \& Kutas, 2011; Barber, van der Meij, \& Kutas, 2013; Li, Niefind, Wang, Sommer, \& Dimigen, 2015; Stites, Payne, \& Federmeier, 2017; Zhang, Li, Wang, \& Wang, 2015; Zhang, Zhen, Liang, \& Mo, 2019). Critically, the ERP parafoveal-on-foveal effect was obtained even if the words with flankers were only presented for $100 \mathrm{~ms}$ (e.g., Barber et al., 2013; Li et al., 2015; Stites et al., 2017), indicating that processing of multiple words may occur very rapidly. Admittedly, the RSVP-with-flanker paradigm still dramatically differs from natural reading (Kornrumpf et al., 2016). Nevertheless, this paradigm offers a simple and elegant alternative to investigate ERP correlates of parafoveal processing, which is feasible for EEG labs without an eye-tracker.

Note that the FRP and RSVP-with-flanker studies not only provide methodological innovations for electrophysiological investigations of reading, but also contribute to a fundamental issue addressed in reading research, that is, whether skilled reading involves a strictly one-word-at-a-time serial processing, or the parallel processing of multiple words at the same time (Reichle, Liversedge, Pollatsek, \& Rayner, 2009; Snell \& Grainger, 2019a; see Schotter \& Payne, 2019; and White, Boynton, \& Yeatman, 2019, for commentaries). Although eye-tracking studies have found evidence for parafoveal-on-foveal effects in favor of parallel processing, the serial processing view can be maintained by arguing that this effect is caused by extralinguistic factors, such as mislocated fixations (for discussions, see Drieghe, 2011; Schotter,
Reichle, \& Rayner, 2014; Snell, Declerck, \& Grainger, 2018). However, such extralinguistic explanations cannot account for the parafoveal-on-foveal effect observed in FRP and RSVP-withflanker studies, and therefore this electrophysiological evidence provides crucial support that foveal and parafoveal word processing can occur in parallel (see Snell, Meade, Meeter, Holcomb, \& Grainger, 2019, for further ERP evidence for parafoveal-on-foveal effects using a flanked lexical decision paradigm).

In addition to the FRP and RSVP-with-flanker studies, another methodological advance also sheds light on the debate concerning serial and parallel processing. The rapid parallel visual presentation (RPVP) paradigm was first combined with an investigation of a syntactic sentence superiority effect in Snell and Grainger (2017). ${ }^{1}$ In this RPVP study, a sequence of four horizontally aligned words was briefly presented (i.e., $200 \mathrm{~ms}$ ). The experimental task was to identify one postcued word within the sequence. Snell and Grainger found that individual words (e.g., sing) are easier to identify in a syntactically correct word sequence (e.g., she can sing now) compared with a scrambled version of the same words (e.g., now she sing can). This behavioral sentence superiority effect has three important implications. First, it demonstrates that simultaneous processing of multiple words is possible, and this parallel processing occurs at a remarkable speed. Second, because semantic constraints were minimized in the syntactically correct sequences used in this study, syntactic representations are the likely source of the effect. Importantly, the sentence superiority effect is assumed to reflect the interactive processing operating between sentence-level structures and word identities which allows sentence-level constraints to influence ongoing word processing (Snell \& Grainger, 2017). In a follow-up ERP study, Wen, Snell, and Grainger (2019) sought the neural index of the sentence superiority effect by combining ERP measures with the RPVP paradigm. The logic of that ERP study was straightforward: if the sentence superiority effect is driven by parallel word processing guided by sentence-level constraints, an N400 reduction should be observed in the syntactically correct sequences relative to the scrambled sequences. And the N400 sentence superiority effect is exactly what was found.

One puzzling aspect of the results of Wen et al. (2019) is why no P600 effect was found given that the P600 is the classic ERP component associated with syntactic processing. One possible explanation is that Wen et al. (2019) used a postcued partial report task instead of the grammaticality judgment task widely used in the P600 literature. There is a general consensus that the P600 effect may be sensitive to the experimental task and that the P600 effect is more likely to be evoked when the task involves an explicit judgment of sentence structure, that is, grammaticality or acceptability judgments (Kuperberg, 2007). In the Wen et al. study, the main task of participants was to identify a single word among the sequence of four words, and it might be differences in

\footnotetext{
${ }^{1}$ The sentence superiority effect has also been investigated in memory research (e.g., Bonhage, Meyer, Gruber, Friederici, \& Mueller, 2017) and auditory sentence processing (e.g., Marslen-Wilson \& Tyler, 1975, 1980). See also Jackson and McClelland (1975) for an early application of the RPVP paradigm, Asano and Yokosawa (2011) for an investigation of sentence superiority in Japanese Kanji using a similar paradigm, and Hagiwara, Soshi, Ishihara, and Imanaka (2007) as well as Ueno and Kluender (2003) for ERP investigations of word order processing.
} 
difficulty in word identification that was driving the N400 effect (e.g., Grainger \& Holcomb, 2009).

To address this unresolved issue, the present study combines the RPVP paradigm with a grammaticality judgment task. The present study set out to test whether the N400 sentence superiority effect can be observed in a grammaticality judgment task with briefly presented sequences of words. Therefore, in Experiment 1 we compared ERP responses to grammatically correct normal word sequences (e.g., the man can run) with ungrammatical scrambled sequences of the same words (e.g., run can man the) in the RPVP paradigm combined with a grammaticality judgment task. If the N400 sentence superiority effect seen in our prior work (Wen et al., 2019) is driven by sentence-level syntactic processing, then it should also be observable in conditions where participants' only task is to make grammaticality judgments.

\section{Experiment 1}

\section{Method}

Participants. Twenty-six native French speakers (21 females; mean age $=22.5$ years, $S D=2.6$ years) received $€ 20$ or course credit for their participation. All participants reported being righthanded, with normal or corrected-to-normal vision, and with no history of neurological, psychiatric or language impairment. Their average LexTALE_Fr vocabulary score (Brysbaert, 2013) was 90.7, $S D=4.1$, and their average self-rated language proficiency score was 9.0, $S D=1.0$ (10-point scale, $1=$ virtually nonexisting, $10=$ perfect $)$. Data from two additional participants were excluded from the analyses because of too many slow drifts in the EEG data.

Materials and design. We constructed 200 four-word sequences in French that were grammatically correct. These 200 four-word sequences were different from those used in Wen et al. (2019), and contained different syntactic structures (e.g., ce plat est bon [the dish is good], je pars en juin [I leave in June], tu bois du rhum [you drink the rum], il te dit cela [he tells you that]). The words in these sequences consisted of two to six letters (average word length $=3.27$ letters). The average word frequency in Zipf values was 6.03, $S D=1.27$ (Ferrand et al., 2010; van Heuven, Mandera, Keuleers, \& Brysbaert, 2014). A scrambled version of every sequence was constructed by switching word positions, and therefore the scrambled sequences were syntactically incorrect (e.g., a grammatically correct sequence: the man can run; the corresponding scrambled sequence: run can man the). Two counterbalanced lists were generated to ensure that in each list all the 200 sequences were presented in only one condition (normal or scrambled) and all the sequences were viewed in both conditions across lists with different participants. Participants were randomly assigned to one of the lists. The full list of materials is presented in the online supplemental materials.

Procedure. The study was approved by the "Comite' de Protection des Personnes SUD-EST IV" (No. 17/051). All participants provided their written informed consent before the experiment started. Participants were seated in a comfortable chair in a dimly lit, electrically shielded booth. Each participant received a unique pseudorandomized presentation order of the stimuli with the same condition (normal vs. scrambled) occurring no more than three times in a row. Stimuli were presented on a CRT monitor (18", $1024 \times 768$ pixels, $75 \mathrm{~Hz}$ ) controlled by OpenSesame (Mathôt, Schreij, \& Theeuwes, 2012) using the PsychoPy back-end (Peirce, 2009). Each trial began with a central fixation cross together with two vertical fixation bars presented for $500 \mathrm{~ms}$, followed by only two vertical fixation bars for $300 \mathrm{~ms}$. Next, a sequence of four words was presented for $200 \mathrm{~ms}$, followed by a backward mask with hash marks (see Figure 1 for an illustration of visual events in Experiment 1). Participants had to decide whether the presented sequence was grammatically correct nor not. Feedback was then provided with a green (correct) or red (incorrect) dot presented for $700 \mathrm{~ms}$. The intertrial interval varied from $600 \mathrm{~ms}$ to $700 \mathrm{~ms}$. Participants were instructed to fixate between the fixation bars and minimize blinks, eye-movements, and body movements. Prior to the experiment, 20 practice trials were used to familiarize the participants with the procedure. A different button was assigned to each yes/no response, and response sides were counterbalanced between participants. Short breaks were provided every 40 trials and the whole experiment lasted approximately two hours (including electrode placement and breaks).

EEG recording and preprocessing. The electroencephalogram (EEG) was recorded with a 64-channel active-electrode system (Biosemi ActiveTwo) at a sample rate of $1024 \mathrm{~Hz}$. Two additional electrodes near $\mathrm{Pz}$ (CMS and DRL) were used for online referencing (Metting van Rijn, Peper, \& Grimbergen, 1990; Schutter, Leitner, Kenemans, \& van Honk, 2006). Six external electrodes were applied: two placed at left and right mastoids for off-line rereferencing, and four placed below and at the outer canthus of each eye to monitor eye movements. The electrode offset was kept below $30 \mathrm{mV}$.

The preprocessing of the EEG data were conducted using the EEGlab/ERPlab Toolbox (Delorme \& Makeig, 2004; LopezCalderon \& Luck, 2014). EEG data were rereferenced to the averaged mastoids and high-pass filtered at $0.1 \mathrm{~Hz}$. The continuous data were then segmented into epochs ranging from -100 to 1,000 $\mathrm{ms}$ after the onset of word sequences. The epochs were baselinecorrected using the prestimulus interval $(-100$ to $0 \mathrm{~ms})$, and

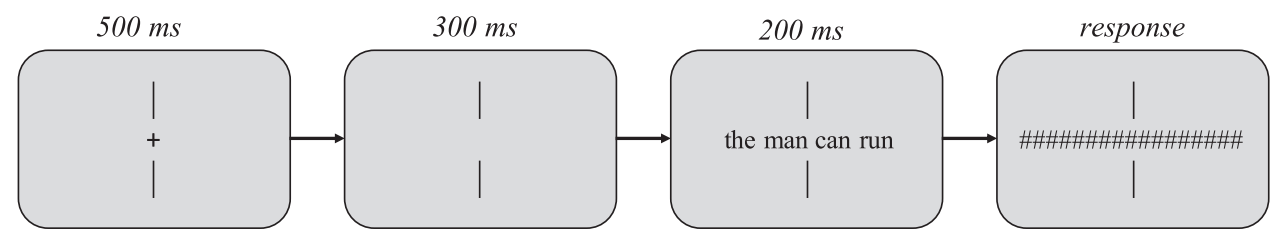

Figure 1. Illustration of the sequence of events in the rapid parallel visual presentation (RPVP) procedure used in Experiment 1. 
low-pass filtered at $30 \mathrm{~Hz}$. Trials with incorrect responses were discarded (16.58\% of the data). Epochs contaminated by drifts and muscle activity were manually removed (5.29\% of the data). For seven participants, epochs containing ocular artifacts were first corrected using an independent component analysis (ICA) algorithm (Jung et al., 2000), otherwise these participants would have more than $20 \%$ of the epochs rejected due to ocular artifacts (Tanner, 2019). Epochs containing ocular artifacts or remaining artifacts after ICA correction were automatically dismissed $(6.77 \%$ of the data). A minimum of 30 epochs were required per condition for each participant (Thierry \& Wu, 2007).

Statistical analysis. To analyze the behavioral data, we conducted a logistic mixed-effects model for the accuracy rates (Jaeger, 2008) and a linear mixed-effects model for the response times using the lme4 package (Bates, Maechler, Bolker, \& Walker, 2015) in R (R Core Team, 2017). Participants and items were included as random effects (Baayen, Davidson, \& Bates, 2008), and random slopes were also included in the analysis (Barr, Levy, Scheepers, \& Tily, 2013). Reaction times of correct responses were analyzed, and values beyond 3.5 standard deviations from the mean of each condition for each participant were discarded as outliers $(0.95 \%)$.

The ERP data were analyzed using the cluster-based random permutation test implemented in FieldTrip (Oostenveld, Fries, Maris, \& Schoffelen, 2011). The cluster-based random permutation approach can effectively control for Type I errors involved in multiple comparisons (see Maris \& Oostenveld, 2007 for details, and see the online supplemental materials for a brief introduction). The cluster-based random permutation test was used as a datadriven method so that the analysis was conducted from $0 \mathrm{~ms}$ to $1,000 \mathrm{~ms}$ poststimulus on all 64 electrodes.

\section{Results}

Behavioral results. Accuracy rates of the grammaticality judgment were significantly higher in the word sequences presented in the normal condition than in the scrambled condition, mean accuracy rates: $87.1 \%$ versus $79.8 \%$ respectively, $z=3.545$, $p<.001$ (see Table 1). Responses to the word sequences presented in the normal condition were faster than to those in the scrambled condition, mean RTs: $848 \mathrm{~ms}$ versus $932 \mathrm{~ms}$ respectively, $t=-3.376, p<.01$ (see Table 2).

ERP results. Only correct trials were included in the ERP analysis. ERP amplitude was reduced in the normal condition

Table 1

Results of Logistic Mixed-Effects Modeling on Accuracy Data (Experiment 1)

\begin{tabular}{|c|c|c|c|c|}
\hline Random effects & \multicolumn{2}{|c|}{ Variance } & \multicolumn{2}{|c|}{$S D$} \\
\hline \multicolumn{5}{|l|}{ Item } \\
\hline Intercept & \multirow{2}{*}{\multicolumn{2}{|c|}{$\begin{array}{l}0.5380 \\
2.5252\end{array}$}} & \multicolumn{2}{|c|}{0.7335} \\
\hline Scrambled vs. Normal & & & \multicolumn{2}{|c|}{1.5891} \\
\hline \multicolumn{3}{|l|}{ Subject } & & \\
\hline Intercept & \multirow{2}{*}{\multicolumn{2}{|c|}{$\begin{array}{l}0.7935 \\
0.8940\end{array}$}} & \multirow{2}{*}{\multicolumn{2}{|c|}{$\begin{array}{l}0.8908 \\
0.9455\end{array}$}} \\
\hline Scrambled vs. Normal & & & & \\
\hline Fixed effects & Estimate & $S E$ & $z$ value & $p$ \\
\hline Scrambled vs. Normal & 0.8641 & 0.2438 & 3.545 & $<.001$ \\
\hline
\end{tabular}

Table 2

Results of Mixed-Effects Modeling on RT Data (Experiment 1)

\begin{tabular}{|c|c|c|c|c|}
\hline Random effects & \multicolumn{2}{|c|}{ Variance } & \multicolumn{2}{|c|}{$S D$} \\
\hline \multicolumn{5}{|l|}{ Item } \\
\hline Intercept & \multirow{2}{*}{\multicolumn{2}{|c|}{$\begin{array}{r}3848 \\
12286\end{array}$}} & \multicolumn{2}{|c|}{62.03} \\
\hline Scrambled vs. Normal & & & & \\
\hline \multicolumn{5}{|l|}{ Subject } \\
\hline Intercept & \multirow{2}{*}{\multicolumn{2}{|c|}{$\begin{array}{l}75664 \\
11924\end{array}$}} & \multirow{2}{*}{\multicolumn{2}{|c|}{$\begin{array}{l}275.07 \\
109.19\end{array}$}} \\
\hline Scrambled vs. Normal & & & & \\
\hline Fixed effects & Estimate & $S E$ & $t$ value & $p$ \\
\hline Scrambled vs. Normal & -81.79 & 24.22 & -3.376 & $<.01$ \\
\hline
\end{tabular}

compared to the scrambled condition from 288 to $499 \mathrm{~ms}$ (cluster with $p=.004$, see Figure 2).

\section{Discussion}

Using the RPVP paradigm with a grammaticality judgment task, Experiment 1 observed a reduction in N400 amplitude in the grammatically correct normal word sequences relative to the ungrammatical scrambled sequences. This result successfully replicates the N400 sentence superiority effect found in Wen et al. (2019), which used a postcued partial report task. The consistent observation of the N400 sentence superiority effect in Experiment 1 and Wen et al. (2019) further suggest that this effect is unlikely to be task-dependent. In line with previous studies (Snell \& Grainger, 2017; Wen et al., 2019), we suggest that this N400 effect reflects parallel processing of multiple words which quickly generates an elementary syntactic representation when this is possible (i.e., in the grammatical sequences), and such syntactic representations then influence ongoing word identification processes. This interpretation is compatible with Hagoort's (2003) syntactic boost account of N400 effects. In this seminal study, a larger N400 effect was found in the combined syntactic and semantic violation condition compared to the pure semantic violation condition, which was explained in terms of syntactic influences on semantic processes. Thus, the syntactic-related N400 effect is not without precedent (see Kutas et al., 2006, for a review). However, given that the critical comparison in Wen et al. (2019) and Experiment 1 involved grammatically correct sequences and ungrammatical scrambled sequences, it is unclear whether the syntactic-driven N400 effect is specific for this contrast. Moreover, this contrast in Experiment 1 involved different behavioral responses, with ungrammatical responses being harder to make than grammatical responses, and this may have had an impact on the ERP effects. Therefore, in Experiment 2, we devised a means to induce an effect of syntactic structure in the grammaticality judgment task but with the same ungrammatical response in the two critical conditions.

\section{Experiment 2}

Experiment 2 also combines the RPVP paradigm and a grammaticality judgment task. The design of Experiment 2 is motivated by our recent work revealing a behavioral transposed-word effect. In a grammaticality judgment study, Mirault, Snell, and Grainger (2018) found higher error rates and slower RTs to the transposed- 

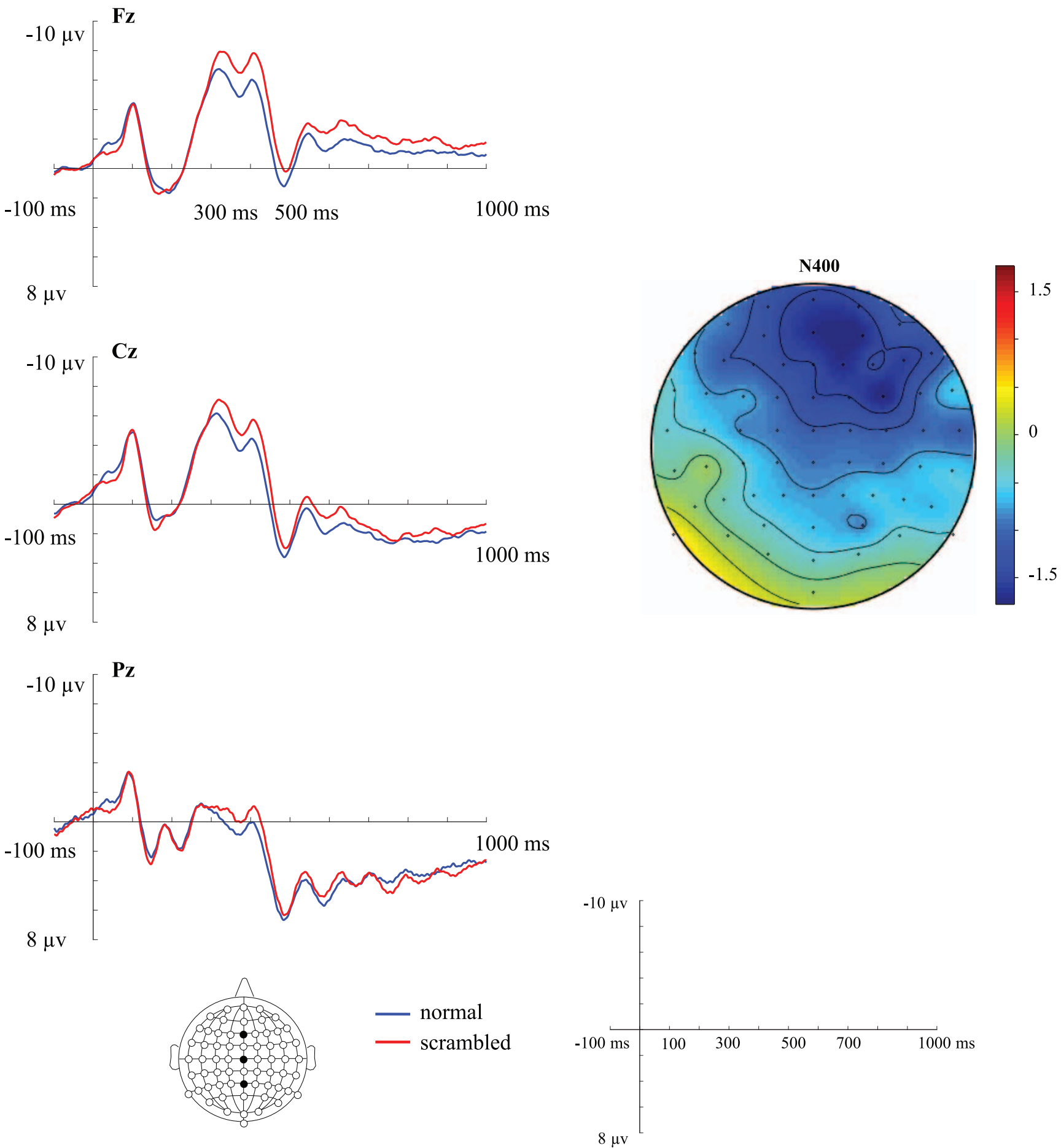

Figure 2. Results of event-related potentials (ERPs) analyses of Experiment 1. Left: ERPs time-locked to the onset of word sequences (Fz, Cz, Pz); Right: Topography of voltage differences (scrambled minus normal) between 289 and $499 \mathrm{~ms}$. See the online article for the color version of this figure.

word sequences (e.g., you that read wrong can be transformed into a grammatical sequence by transposing the two adjacent central words: that read into read that) compared with control sequences (e.g., you that read worry, which cannot be transformed in to a grammatical sequence by transposing any two adjacent words). In line with Snell and Grainger (2017); Mirault et al. (2018) suggested that an initial representation of sentence structure can be quickly generated, and this elementary syntactic representation 
constrains possible word candidates at each position. The combination of such top-down syntactic constraints and the noisy bottom-up encoding of word order drives the transposed-word effect (see Snell \& Grainger, 2019b, for further evidence). The transposed-word effect is taken as evidence against the persisting notion of a strictly serial one-word-at-a-time left-to-right word encoding, although it is well-established that eye movements during reading do not simply move from left-to-right. Such serial processing would have resulted in the detection of incorrect word ordering in the transposed-word condition (Reichle et al., 2009; Snell \& Grainger, 2019a).

Apart from supporting parallel word processing, the transposedword effect reported by Mirault et al. (2018) also appeals to two well-known accounts of sentence parsing, namely the goodenough account (Ferreira, 2003; Ferreira, Bailey, \& Ferraro, 2002; Ferreira \& Lowder, 2016; Ferreira \& Patson, 2007; Gigerenzer, 2000; Sanford, 2002; Townsend \& Bever, 2001) and the noisychannel account (Gibson, Bergen, \& Piantadosi, 2013). According to the good-enough account of parsing, readers can rely on heuristics to build quick but imperfect syntactic representations of the written input, and readers' failure in noticing errors in a sentence is therefore to be expected. On the basis of such an assumption, word position coding during sentence reading is not completely precise (just good-enough), giving rise to the transposed-word effect. Likewise, the noisy-channel account also assumes that readers can understand imperfect sentences, and further predicts that readers' recovery from erroneous input depends on the distance between the inaccurate and correct counterparts. Taking Mirault et al. (2018) as an example, switching two adjacent words is enough to amend a transposed-word sequence (e.g., changing that read into read that in you that read wrong), whereas repairing a control sequence (you that read worry) involves the switching plus an additional replacement (changing that read into read that, and replacing worry as wrong). Consequently, repairing the control sequences is more difficult than the transposed sequences, and thus ungrammatical decisions are easier to make for the control sequence.

Following Mirault et al. (2018), Experiment 2 also investigates the transposed-word effect and thus focuses on the ERP responses to two types of ungrammatical sequences, that is, the transposedword sequences and the control sequences. Under the hypothesis that transposed-word effects reflect the partial activation of syntactic structures that suggest the presence of a grammatically correct sequence of words, then we expect to observe a reduced N400 amplitude in the transposed-word condition relative to the control condition. Here, it is important to note that the transposedword condition that is expected to reduce N400 amplitude should generate the slowest RTs and greatest errors. This is the opposite of Experiment 1 where faster RTs and less errors were observed in the grammatically correct normal sequences that caused a reduced N400.

\section{Method}

Participants. Twenty-six native French speakers (18 females; mean age $=23.2$ years, $S D=2.9$ years) received $€ 20$ or course credit for their participation. One participant had also participated in Experiment 1. All participants reported being right-handed, with normal or corrected-to-normal vision, and with no history of neurological, psychiatric or language impairment. Their average LexTALE_Fr vocabulary score (Brysbaert, 2013) was 91.1, SD = 4.4 , and their average self-rated language proficiency score was $8.7, S D=1.3$ (10-point scale, $1=$ virtually nonexisting, $10=$ perfect). Data from an additional two participants were excluded from the analyses because of excessive eyeblinks or high error rates $(>25 \%)$.

Materials and design. We constructed a new set of grammatically correct sequences to generate the critical stimuli. One hundred sixty four-word sequences were first constructed, and then the last words in those sequences were replaced so as to create the corresponding ungrammatical sequences (e.g., the man can run vs. the man can big). Next, the words at positions 2 and 3 were transposed in all the 160 pairs of sequences. The transposed-word version of grammatically correct sequences was referred to as the transposed-word condition (e.g., the can man run), whereas the transposed-word version of ungrammatical sequences was referred to as the control condition (e.g., the can man big). The words in all these sequences consisted of two to seven letters (average word length $=4.25$ letters). The average word frequency in Zipf values was 5.79, $S D=1.09$ (Ferrand et al., 2010; van Heuven et al., 2014). Two counterbalanced lists were created to ensure that in each list all the 160 pairs of sequences were presented in only one condition (transposed-word vs. control condition) and all the pairs were viewed in both conditions across lists. Participants were randomly assigned to one of the lists. Because all the critical stimuli in both conditions require No responses, another 160 grammatically correct four-word sequences were included as fillers (e.g., the guy is tall) to have an equal number of Yes and No responses. The words in the grammatically correct filler sequences matched the words used in the critical stimuli in word length (average word length: 4.25 letters) and frequency (average word frequency in Zipf values $=5.96, S D=1.19$ ). The full list of materials is presented in the online supplemental materials.

Procedure. The procedure was identical to the procedure used in Experiment 1 except for one aspect (see Figure 3 for an illustration of visual events in Experiment 2). The backward mask

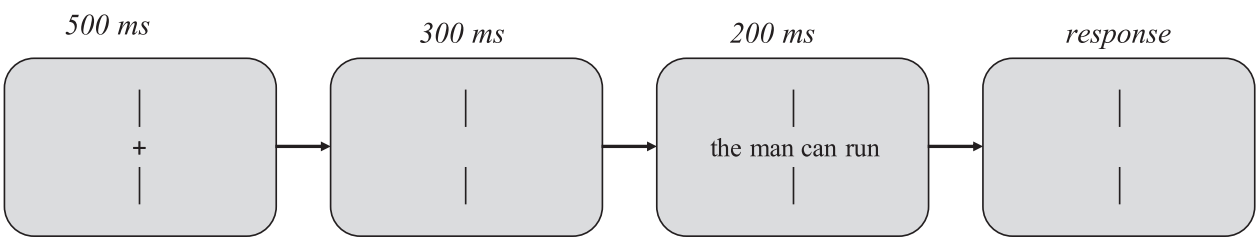

Figure 3. Illustration of the sequence of events in the rapid parallel visual presentation (RPVP) procedure used in Experiment 2. 
was not used in Experiment 2 to avoid visual event-related potentials generated by the appearance of masks overlapping with the N400 component.

EEG recording and preprocessing. The same EEG recording setup and EEG preprocessing pipeline were used for Experiment 2 as in Experiment 1. Trials with incorrect responses were discarded (11.69\% of the data). Epochs contaminated by drifts and muscle activity were manually removed $(3.39 \%$ of the data). For 13 participants, epochs containing ocular artifacts were first corrected using an independent component analysis (ICA) algorithm (Jung et al., 2000), otherwise these participants would have more than $20 \%$ of the epochs rejected due to ocular artifacts (Tanner, 2019). Epochs containing ocular artifacts or remaining artifacts after ICA correction were automatically dismissed $(4.65 \%$ of the data).

Statistical analysis. In line with Experiment 1, we conducted a logistic mixed-effects model for the accuracy rates, a linear mixed-effects model for the response times, and the cluster-based random permutation test for the ERP data. Reaction times of correct responses were analyzed, and values beyond 3.5 standard deviations from the mean of each condition for each participant were discarded as outliers $(0.94 \%)$. The ERP results from Experiment 1 were used to guide the ERP analysis of Experiment 2. Given that a significant cluster was found within the N400 time window (around 290 to $500 \mathrm{~ms}$ ) in Experiment 1, we focused on this time window in Experiment 2. The ERP amplitude of this a priori selected time window was first averaged for each electrode and each condition, and then a cluster-based random permutation test was applied on all 64 electrodes. Therefore, cluster-based random permutation tests in Experiment 2 were conducted over electrode. The logic is that the cluster-based random permutation test can be conservative when used as a pure data-driven approach, and an a priori region of interest or time window can improve the sensitivity of the analysis (for a similar approach, see Wen, Filik, \& van Heuven, 2018).

\section{Results}

Behavioral results. Consistent with Mirault et al. (2018), accuracy rates were significantly higher in the control condition than in the transposed-word condition, mean accuracy rates: $90.5 \%$ versus $82.4 \%$ respectively, $z=8.248, p<.001$ (see Table 3 ). In addition, participants were quicker in judging the control sequences as ungrammatical relative to the transposed-word sequences, mean RTs: $1183 \mathrm{~ms}$ versus $1230 \mathrm{~ms}$ respectively, $t=-3.481, p<.01$ (see Table 4).

ERP results. Only correct trials were included in the ERP analysis. Testing for an N400 effect in the a priori time window (290-500 ms poststimulus), the cluster-based permutation tests revealed a significant reduction in N400 amplitude in the transposed-word condition compared to the control condition (cluster with $p=.0382$, see Figure 4). ${ }^{2}$

\section{Discussion}

Experiment 2 used the transposed-word effect seen in grammaticality judgments (Mirault et al., 2018) to compare conditions requiring the same ungrammatical response. As in Experiment 1, the grammaticality judgment task was combined with the RPVP
Table 3

Results of Logistic Mixed-Effects Modeling on Accuracy Data (Experiment 2)

\begin{tabular}{|c|c|c|c|c|}
\hline Random effects & \multicolumn{2}{|c|}{ Variance } & \multicolumn{2}{|c|}{$S D$} \\
\hline Item & \multirow{2}{*}{\multicolumn{2}{|c|}{0.4509}} & \multirow{2}{*}{\multicolumn{2}{|c|}{0.6715}} \\
\hline Intercept & & & & \\
\hline Subject & & & & \\
\hline Intercept & \multicolumn{2}{|c|}{0.5379} & \multicolumn{2}{|c|}{0.7334} \\
\hline Fixed effects & Estimate & $S E$ & $z$ value & $p$ \\
\hline Scrambled vs. Normal & 0.81364 & 0.09865 & 8.248 & $<.001$ \\
\hline
\end{tabular}

Note. The maximal model failed to converge, and a backward model selection procedure was used. The random slopes of items were first removed, and then the random slopes of subjects. The complex model was compared with the simpler model using a chi-squared test. We proceeded with the simpler model because the chi-squared test was not significant.

paradigm. The behavioral transposed-word effect reported in Mirault et al. (2018) was again observed, which supports parallel processing as well as the good-enough account and the noisy channel account of syntactic parsing. As expected, an attenuated $\mathrm{N} 400$ was observed in the transposed-word condition (e.g., you that read wrong, transposing the two central words forms a grammatically correct sequence) relative to the control condition (e.g., you that read worry, transposing any two words still forms an ungrammatical sequence). This result is consistent with the hypothesis that parallel word processing can quickly generate an initial representation of sentence structure, which then constrains possible word candidates at each position (Mirault et al., 2018). Hence the transposed-word effect was attributed to the joint effect of the top-down sentence-level constraints and the noisy bottom-up processing of word order (see also Pegado \& Grainger, 2019; and Snell \& Grainger, 2019b). The results of Experiment 2 therefore extend the findings of Experiment 1 and Wen et al. (2019) by providing another demonstration of a syntactically driven N400 effect in RPVP generated by a different experimental manipulation.

\section{General Discussion}

The present study reports two experiments that for the first time combined the RPVP paradigm and a grammaticality judgment task with EEG recordings. Sequences of four words were presented simultaneously for $200 \mathrm{~ms}$, and participants were required to decide whether these sequences were grammatical or not. In Experiment 1 , the four words consisted of either a grammatically correct sentence (e.g., the man can run) or an ungrammatical scrambled sequence of the same words (e.g., run can man the). The key finding is that a reduction in N400 amplitude was observed in the grammatical sequences compared to the scrambled sequences. This result replicates the N400 sentence superiority

\footnotetext{
${ }^{2}$ The finding remained the same when using the time window between 300 and $500 \mathrm{~ms}$. We also conducted a conventional ANOVA analysis on ERP mean amplitudes, which revealed the same finding. Additional analyses on the later time-window $(500-800 \mathrm{~ms})$ did not reveal any significant effect, although the numerically larger amplitude in the control condition (see $\mathrm{Cz}$ in Figure 4) seems to be a P600-like effect.
} 
Table 4

Results of Mixed-Effects Modeling on RT Data (Experiment 2)

\begin{tabular}{|c|c|c|c|c|}
\hline Random effects & \multicolumn{2}{|c|}{ Variance } & \multicolumn{2}{|c|}{$S D$} \\
\hline \multicolumn{5}{|l|}{ Item } \\
\hline Intercept & \multicolumn{2}{|c|}{5038} & \multicolumn{2}{|c|}{70.98} \\
\hline \multicolumn{5}{|l|}{ Subject } \\
\hline Intercept & \multirow{2}{*}{\multicolumn{2}{|c|}{$\begin{array}{r}102127 \\
1750\end{array}$}} & \multirow{2}{*}{\multicolumn{2}{|c|}{$\begin{array}{r}319.57 \\
41.83\end{array}$}} \\
\hline Transposed-word vs. Control & & & & \\
\hline Fixed effects & Estimate & $S E$ & $t$ value & $p$ \\
\hline Transposed-word vs. Control & -50.56 & 14.53 & -3.481 & $<.01$ \\
\hline
\end{tabular}

Note. The maximal model failed to converge, and a backward model selection procedure was used. The random slopes of items were first removed, and then the random slopes of subjects. The complex model was compared to the simpler model using an ANOVA test. The more complex model was chosen because the ANOVA test was significant.

effect obtained using a postcued partial report procedure combined with the same RPVP paradigm (Wen et al., 2019). The present findings therefore suggest that the N400 sentence superiority effect reported by Wen et al. is not a reflection of differences in ease of word identification as a function of surrounding context but most likely reflects the interaction between sentence-level processing and word identification. The general idea is that an elementary syntactic representation of the word sequence can be rapidly activated as a result of parallel word processing, and this syntactic representation then constrains ongoing word identification processes via feedback connections. The fact that in the present study we found a very similar reduction in N400 amplitude when participants had to respond to the complete sequence of words rather than a single word, confirms the hypothesized role of syntactic processing in driving the $\mathrm{N} 400$ sentence superiority effect.

Crucially, Experiment 2 contrasted two types of ungrammatical sequences, the transposed-word sequences (e.g., you that read wrong) and the control sequences (e.g., you that read worry). This allowed us to test for effects of syntactic structure in conditions where participants made the same ungrammatical response to word sequences. Furthermore, here the transposed-word condition that was predicted to reduce N400 amplitude was the condition that was expected to generate the slowest RTs and highest error rates. Indeed, Experiment 2 replicated the behavioral findings of Mirault et al. (2018) whereby participants made more errors and were slower in judging the transposed-word sequences (e.g., you that read wrong) as ungrammatical compared with the control sequences (e.g., you that read worry). We predicted a reduced N400 amplitude in the transposedword condition because this condition was expected to provide evidence in favor of the presence of a correct sentence.

The N400 transposed-word effect was indeed what we observed. To our knowledge, we provide the first neurophysiological demonstration of the transposed-word effect. This effect is analogous to the N400 transposed-letter effect in visual word recognition studies (e.g., Carreiras, Vergara, \& Perea, 2007; Vergara-Martínez, Perea, Gómez, \& Swaab, 2013), which reflects the coarse coding of letter positions in words (Grainger \& Holcomb, 2009; Grainger \& Ziegler, 2011). In a similar vein, the N400 transposed-word effect indicates the noisy bottom-up processing of word order as the consequence of good-enough heuristic mechanisms during sentence reading (Ferreira, 2003; Ferreira et al., 2002; Ferreira \&
Lowder, 2016; Ferreira \& Patson, 2007; Gigerenzer, 2000; Sanford, 2002; Townsend \& Bever, 2001). The combination of such noisy bottom-up processing with top-down syntactic constraints drives the transposed-word effect.

Taken together, our results are clear-cut. Both experiments observed an N400 effect in conditions where participants were required to make grammaticality judgments about the entire sequence of words. Therefore, we take this N400 effect as a signature of syntactic processing in the brain given that this effect is driven by the processing of word combinations where semantic relatedness was minimized. It is important to note that the N400 effect well precedes participants' behavioral responses, which occurred at least $800 \mathrm{~ms}$ after the onset of word sequences. Hence the observed N400 effect is not confounded by behavioral responses or any strategic factors. Furthermore, the N400 effect is not just a processing difficulty effect given that the condition that generated the largest N400 amplitude was the condition that generated the slowest RTs and greatest errors in Experiment 1, whereas exactly the opposite was true in Experiment 2.

At first glance, the syntactically driven N400 effect observed in the present study appears at odds with the syntactic P600 effect obtained in traditional RSVP studies. Given that the N400 effect was obtained in both a postcued partial report task (Wen et al., 2019) and a grammaticality judgment task (the present study), we reject the task-dependent account to explain the absence of the P600 effect, the well-established neural index of syntactic processing. We would argue that our syntactically driven N400 effects are fundamentally different from the P600 effect observed in RSVP studies (for more discussion on N400 and P600 effects, see Dwivedi, 2013; Kaan, Harris, Gibson, \& Holcomb, 2000). In the RSVP studies, when a word is presented to participants, participants have to integrate this word with the prior words in the sentence. However, integration difficulty occurs when encountering syntactic processing obstacles, and an enhanced P600 is typically observed in the critical words that trigger such difficulty, for example, eating is the critical word in the syntactically anomalous sentence the cat will eating the fish. It is noteworthy that RSVP studies not only find a P600 effect elicited by the critical word embedded in the sentences, but also report a N400 effect elicited by the final words of the syntactically-incorrect sentences, for example, fish is the sentence-final word in the previous example (e.g., Hagoort, Brown, \& Groothusen, 1993; Osterhout \& Mobley, 1995; Osterhout \& Nicol, 1999). In addition, the N400 effect may also appear if the critical words appear in the sentence-final positions, for example, himself is the critical word in the girl helps himself (e.g., Hagoort, 2003; Hagoort \& Brown, 1999; Osterhout, 1997). The sentence-final N400 effect is generally interpreted as processing difficulty in generating semantic representations of syntactically ill-formed sentences (Hagoort et al., 1993; Osterhout, 1997; Osterhout \& Holcomb, 1992). ${ }^{3}$ In other words, the finalword N400 effect reflects a global processing of semantics and the critical-word P600 effect indicates a local difficulty in syntactic processing. Such incremental sentential processing in the RSVP paradigm stands in clear contrast to parallel proceeding in the

\footnotetext{
${ }^{3}$ Another slightly different view of the final-word N400 effect is that it may reflect a sentence wrap-up effect (for a recent review, see Stowe, Kaan, Sabourin, \& Taylor, 2018).
} 
RPVP paradigm. Furthermore, the cognitive mechanisms underlying the P600 effect of syntactic processing difficulty (e.g., syntactic violations or ambiguities) and our N400 effect (i.e., sentence superiority or transposed-word effects) are obviously distinct.

Admittedly, another possibility is that the P600 effect in response to syntactic difficulty is restricted to the RSVP paradigm. The fact that the semantic N400 component precedes the syntactic P600 component is seemingly in contrast to the traditional syntaxfirst view of language processing (e.g., Friederici \& Weissenborn, 2007) or the parallel view of semantic and syntactic processing (e.g., Jackendoff, 2007). ${ }^{4}$ If the relatively late syntactic P600 effect is attributable to the serial presentation used in RSVP, an early effect is expected with the parallel presentation procedure of RPVP. Future studies should examine this issue by presenting syntactically ill-formed sentences in the RPVP paradigm. In short, the most parsimonious conclusion is that our observations of syntactically driven N400 effects are not necessarily in contradiction with the classic P600 literature because of differences in the linguistic phenomena under investigation and presentation techniques.

The observed ERP evidence of the sentence superiority effect and transposed-word effect fits well with the idea that parallel processing of multiple words is possible during sentence reading (Engbert, Nuthmann, Richter, \& Kliegl, 2005; Grainger, 2018; Snell \& Grainger, 2019a; Snell, Meeter, \& Grainger, 2017). This conclusion is fully compatible with the parafoveal-on-foveal effect obtained in the FRP and RSVP-with-flanker studies as discussed in the Introduction. Although growing evidence from electrophysiological investigations has suggested that the parallel word processing account is more plausible, the one-word-at-a-time incremental processing approach still dominates current theories of reading (for a review, see Reichle et al., 2009). It should be noted that these popular serial theories are mainly proposed on the basis of behavioral eye-tracking data rather than ERP data. However, ERP data provide a direct real-time measurement of reading, and these electrophysiological studies are abundant and essential in empirical investigations. Accordingly, theories of reading will be more informative if they consider electrophysiological data as well. Therefore, we tentatively suggest that future theoretical models of reading should take neural data into accounts in order to capture the complete picture of cognitive mechanisms underlying reading (see Brouwer, Crocker, Venhuizen, \& Hoeks, 2017, for a neurocomputational approach).

Overall, the present study demonstrates that the RPVP paradigm is a useful methodology in electrophysiological investigations of reading comprehension which complements the mainstream RSVP as well as other newly developed methods (e.g., coregistering eye-tracking and EEG, RSVP-with-flanker, and the self-paced ERP paradigm: Payne \& Federmeier, 2017). Of course, we acknowledge that the RPVP paradigm is not exactly the same as natural reading, but we would argue that it provides a useful method for demonstrating that, in principle, words can be processed in parallel. We would further argue that this paradigm helps avoid some potential complexities or confounds in alternative paradigms (e.g., temporal overlap issues in FRP studies) and thus provides a potentially better focus on the basic mechanisms involved in skilled reading. However, one might question whether the parallel presentation of RPVP forces participants to process the words in parallel, contrary to natural reading. Although this pos- sibility cannot be ruled out with our own data, it is noteworthy that such parallel processing is observed in other studies using different paradigms (see the FRP and RSVP-with-flanker studies discussed in the Introduction). Based on the converging evidence from different paradigms, we believe that it is reasonable to suggest that parallel word processing also occurs during natural reading. Another speculation concerning the RPVP paradigm is whether this specific presentation procedure encourages heuristic processing, thus driving the transposed-word effect. It is worth pointing out that the transposed-word effect was originally discovered by Mirault et al. (2018) without using the RPVP paradigm. In Mirault et al. (2018), the word sequences remained on screen until participants responded. Moreover, the classic evidence of good-enough heuristic processing comes from studies using various paradigms (e.g., the RSVP paradigm: Christianson, Hollingworth, Halliwell, \& Ferreira, 2001; van Herten, Chwilla, \& Kolk, 2006; the selfpaced reading paradigm: Dwivedi, 2013; for a recent review, see Ferreira \& Lowder, 2016). By virtue of these different research strands, we believe that it is unlikely that heuristic processing is a strategy adopted specifically in the RPVP paradigm.

There are nevertheless some potential caveats of the existing RPVP studies, which will require clarifications in future studies. First, although semantic factors were minimized in the investigation of the sentence superiority effect (Snell \& Grainger, 2017; Wen et al., 2019), it is still possible that a sentence-level semantic representation was driving the effect. Future research using syntactically correct but semantically uninterpretable sequences as well as semantically interpretable but anomalous sequences will allow us to separate out syntactic and semantic contributions to the sentence superiority effect (see Marslen-Wilson \& Tyler, 1975, 1980, for an example of how to disassociate syntactic and semantic factors during sentence processing). Additionally, it is unclear whether word co-occurrence frequency contributes to the sentence superiority effect, and thus future research could manipulate word co-occurrence frequency in both the grammatically correct and ungrammatical sequences. Although the role of word cooccurrence frequency has not been directly explored, a bilingual sentence superiority effect was observed where the potential role of word co-occurrence frequency was minimized (Declerck, Wen, Snell, Meade, \& Grainger, in press). Using the same RPVP paradigm, Declerck et al. (in press) found that word identification was more accurate in an interpretable grammatical sequence composed of two French and two English words (e.g., ses feet sont big, ses and sont mean his and are in French) compared with an ungrammatical sequence (e.g., sont feet ses big). Given that the cooccurrence frequency of grammatical sequences with intermixing French and English words must be very low, the bilingual sentence

\footnotetext{
${ }^{4}$ We note here that the left anterior negativity (LAN: Friederici, Hahne, \& Mecklinger, 1996), another ERP component associated with syntactic processing, may appear earlier than the N400. However, the LAN effect is generally limited to morphosyntactic violations and the occurrence of LAN is not systematically consistent across studies (Caffarra, Mendoza, \& Davidson, 2019; Kaan, 2009; Molinaro et al., 2011; Tanner, 2015; Tanner \& Van Hell, 2014). In contrast, the P600 is sensitive to most syntactic manipulations, and consequently is considered as the neural index of syntactic processing in general.
} 

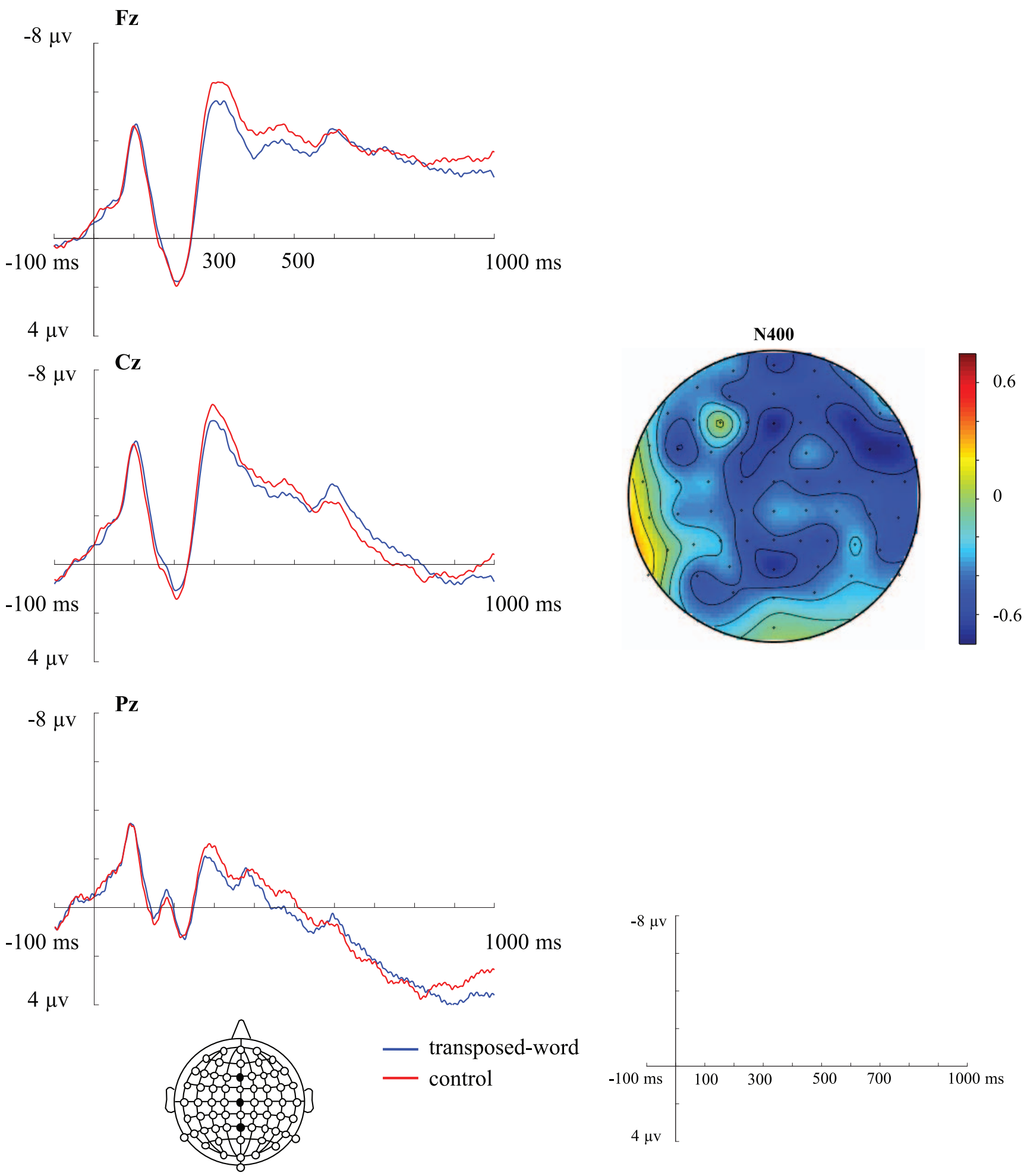

Figure 4. Results of event-related potentials (ERPs) analyses of Experiment 2. Left: ERPs time-locked to the onset of word sequences $(\mathrm{Fz}, \mathrm{Cz}, \mathrm{Pz})$; Right: Topography of voltage differences (control minus transposed-word) between 290 and $500 \mathrm{~ms}$. See the online article for the color version of this figure. 
superiority effect cannot be driven by word co-occurrence frequency. Furthermore, another speculative issue of the present study as well as Wen et al. (2019) is that word sequences only consist of four words. It is true that the length of word sequences is highly constrained, but various sentence structures were used in our studies so that it is unlikely that our conclusions are limited to specific types of sentences. Given that the beauty of language is its infinite nature, it is impossible to test all the sentence types in one single experiment, and this limitation is shared across all the studies on sentence reading. Nevertheless, future RPVP explorations could use word sequences with various length to further test the sentence superiority and transposed-word effects.

In conclusion, the present study introduces the RPVP as a new and useful approach in electrophysiological investigations of reading and addresses the central question of serial and parallel processing views in skilled reading. The observations of the sentence superiority and transposed-word effects in terms of the reduced N400 reflect the influence of the syntactic representations on word identification. Our findings suggest that words presented in parallel can be quickly processed by skilled readers, and we advocate the use of RPVP as a complementary approach in future studies to better understand the neural and cognitive underpinnings of reading comprehension.

\section{References}

Asano, M., \& Yokosawa, K. (2011). Rapid extraction of gist from visual text and its influence on word recognition. Journal of General Psychology, 138, 127-154. http://dx.doi.org/10.1080/00221309.2010.542510

Baayen, R. H., Davidson, D. J., \& Bates, D. M. (2008). Mixed-effects modeling with crossed random effects for subjects and items. Journal of Memory and Language, 59, 390-412. http://dx.doi.org/10.1016/j.jml.2007.12 .005

Baccino, T., \& Manunta, Y. (2005). Eye-fixation-related potentials: Insight into parafoveal processing. Journal of Psychophysiology, 19, 204-215. http://dx.doi.org/10.1027/0269-8803.19.3.204

Barber, H. A., Ben-Zvi, S., Bentin, S., \& Kutas, M. (2011). Parafoveal perception during sentence reading? An ERP paradigm using rapid serial visual presentation (RSVP) with flankers. Psychophysiology, 48, 523531. http://dx.doi.org/10.1111/j.1469-8986.2010.01082.x

Barber, H. A., Doñamayor, N., Kutas, M., \& Münte, T. (2010). Parafoveal N400 effect during sentence reading. Neuroscience Letters, 479, 152156. http://dx.doi.org/10.1016/j.neulet.2010.05.053

Barber, H. A., van der Meij, M., \& Kutas, M. (2013). An electrophysiological analysis of contextual and temporal constraints on parafoveal word processing. Psychophysiology, 50, 48-59. http://dx.doi.org/10.1111/j.1469-8986 .2012.01489.x

Barr, D. J., Levy, R., Scheepers, C., \& Tily, H. J. (2013). Random effects structure for confirmatory hypothesis testing: Keep it maximal. Journal of Memory and Language, 68, 255-278. http://dx.doi.org/10.1016/j.jml .2012 .11 .001

Bates, D., Maechler, M., Bolker, B., \& Walker, S. (2015). Fitting linear mixed-effects models using lme4. Journal of Statistical Software, 67, 1-48. http://dx.doi.org/10.18637/jss.v067.i01

Bonhage, C. E., Meyer, L., Gruber, T., Friederici, A. D., \& Mueller, J. L. (2017). Oscillatory EEG dynamics underlying automatic chunking during sentence processing. NeuroImage, 152, 647-657. http://dx.doi.org/ 10.1016/j.neuroimage.2017.03.018

Brouwer, H., Crocker, M. W., Venhuizen, N. J., \& Hoeks, J. C. J. (2017). A neurocomputational model of the $\mathrm{N} 400$ and the $\mathrm{P} 600$ in language processing. Cognitive Science, 41, 1318-1352. http://dx.doi.org/10.1111/cogs .12461
Brysbaert, M. (2013). LEXTALE_FR: A fast, free, and efficient test to measure language proficiency in French. Psychologica Belgica, 53, 23-37. http://dx.doi.org/10.5334/pb-53-1-23

Caffarra, S., Mendoza, M., \& Davidson, D. (2019). Is the LAN effect in morphosyntactic processing an ERP artifact? Brain and Language, 191, 9-16. http://dx.doi.org/10.1016/j.bandl.2019.01.003

Carreiras, M., Vergara, M., \& Perea, M. (2007). ERP correlates of transposed-letter similarity effects: Are consonants processed differently from vowels? Neuroscience Letters, 419, 219-224. http://dx.doi.org/10 .1016/j.neulet.2007.04.053

Christianson, K., Hollingworth, A., Halliwell, J. F., \& Ferreira, F. (2001). Thematic roles assigned along the garden path linger. Cognitive Psychology, 42, 368-407. http://dx.doi.org/10.1006/cogp.2001.0752

Declerck, M., Wen, Y., Snell, J., Meade, G., \& Grainger, J. (in press). Unified syntax in the bilingual mind. Psychonomic Bulletin \& Review. http://dx.doi.org/10.3758/s13423-019-01666-x

Degno, F., Loberg, O., Zang, C., Zhang, M., Donnelly, N., \& Liversedge, S. P. (2019). Parafoveal previews and lexical frequency in natural reading: Evidence from eye movements and fixation-related potentials. Journal of Experimental Psychology: General, 148, 453-474. http://dx .doi.org/10.1037/xge0000494

Delorme, A., \& Makeig, S. (2004). EEGLAB: An open source toolbox for analysis of single-trial EEG dynamics including independent component analysis. Journal of Neuroscience Methods, 134, 9-21. http://dx.doi.org/ 10.1016/j.jneumeth.2003.10.009

Dimigen, O., Kliegl, R., \& Sommer, W. (2012). Trans-saccadic parafoveal preview benefits in fluent reading: A study with fixationrelated brain potentials. NeuroImage, 62, 381-393. http://dx.doi.org/ 10.1016/j.neuroimage.2012.04.006

Dimigen, O., Sommer, W., Hohlfeld, A., Jacobs, A. M., \& Kliegl, R. (2011). Coregistration of eye movements and EEG in natural reading: Analyses and review. Journal of Experimental Psychology: General, 140, 552-572. http://dx.doi.org/10.1037/a0023885

Drieghe, D. (2011). Parafoveal-on-foveal effects on eye movements during reading. In S. P. Liversedge, I. D. Gilchrist, \& S. Everling (Eds.), The Oxford handbook of eye movements (pp. 839-855). New York, NY: Oxford University Press.

Dwivedi, V. D. (2013). Interpreting quantifier scope ambiguity: Evidence of heuristic first, algorithmic second processing. PLOS ONE, 8, e81461. http://dx.doi.org/10.1371/journal.pone.0081461

Engbert, R., Nuthmann, A., Richter, E. M., \& Kliegl, R. (2005). SWIFT: A dynamical model of saccade generation during reading. Psychological Review, 112, 777-813. http://dx.doi.org/10.1037/0033-295X.112.4.777

Ferrand, L., New, B., Brysbaert, M., Keuleers, E., Bonin, P., Méot, A., . . Pallier, C. (2010). The French Lexicon Project: Lexical decision data for 38,840 French words and 38,840 pseudowords. Behavior Research Methods, 42, 488-496. http://dx.doi.org/10.3758/BRM.42.2.488

Ferreira, F. (2003). The misinterpretation of noncanonical sentences. Cognitive Psychology, 47, 164-203. http://dx.doi.org/10.1016/S0010-0285 (03)00005-7

Ferreira, F., Bailey, K. G. D., \& Ferraro, V. (2002). Good-enough representations in language comprehension. Current Directions in Psychological Science, 11, 11-15. http://dx.doi.org/10.1111/1467-8721.00158

Ferreira, F., \& Lowder, M. W. (2016). Prediction, information structure, and good-enough language processing. Psychology of Learning and Motivation, 65, 217-247. http://dx.doi.org/10.1016/bs.plm.2016.04.002

Ferreira, F., \& Patson, N. D. (2007). The 'good enough' approach to language comprehension. Language and Linguistics Compass, 1, 71-83. http://dx.doi.org/10.1111/j.1749-818X.2007.00007.x

Friederici, A. D., Hahne, A., \& Mecklinger, A. (1996). Temporal structure of syntactic parsing: Early and late event-related brain potential effects. Journal of Experimental Psychology: Learning, Memory, and Cognition, 22, 1219-1248. http://dx.doi.org/10.1037/0278-7393.22.5.1219 
Friederici, A. D., \& Weissenborn, J. (2007). Mapping sentence form onto meaning: The syntax-semantic interface. Brain Research, 1146, 50-58. http://dx.doi.org/10.1016/j.brainres.2006.08.038

Gibson, E., Bergen, L., \& Piantadosi, S. T. (2013). Rational integration of noisy evidence and prior semantic expectations in sentence interpretation. Proceedings of the National Academy of Sciences of the United States of America, 110, 8051-8056. http://dx.doi.org/10.1073/pnas 1216438110

Gigerenzer, G. (2000). Adaptive thinking: Rationality in the real world. New York, NY: Oxford University Press.

Grainger, J. (2018). Orthographic processing: A 'mid-level' vision of reading. Quarterly Journal of Experimental Psychology: Human Experimental Psychology, 71, 335-359. http://dx.doi.org/10.1080/17470218.2017.1314515

Grainger, J., \& Holcomb, P. J. (2009). Watching the word go by: On the time-course of component processes in visual word recognition. Language and Linguistics Compass, 3, 128-156. http://dx.doi.org/10.1111/j.1749818X.2008.00121.X

Grainger, J., \& Ziegler, J. C. (2011). A dual-route approach to orthographic processing. Frontiers in Psychology, 2, 54. http://dx.doi.org/10.3389/fpsyg .2011 .00054

Hagiwara, H., Soshi, T., Ishihara, M., \& Imanaka, K. (2007). A topographical study on the event-related potential correlates of scrambled word order in Japanese complex sentences. Journal of Cognitive Neuroscience, 19, 175-193. http://dx.doi.org/10.1162/jocn.2007.19.2.175

Hagoort, P. (2003). Interplay between syntax and semantics during sentence comprehension: ERP effects of combining syntactic and semantic violations. Journal of Cognitive Neuroscience, 15, 883-899. http://dx .doi.org/10.1162/089892903322370807

Hagoort, P. (2009). Reflections on the neurobiology of syntax. In D. Bickerton \& E. Szathmáry (Eds.), Biological foundations and origin of syntax (pp. 279-298). Cambridge, MA: MIT Press.

Hagoort, P., \& Brown, C. M. (1999). Gender electrified: ERP evidence on the syntactic nature of gender processing. Journal of Psycholinguistic Research, 28, 715-728. http://dx.doi.org/10.1023/A:1023277213129

Hagoort, P., Brown, C., \& Groothusen, J. (1993). The syntactic positive shift (sps) as an erp measure of syntactic processing. Language and Cognitive Processes, 8, 439-483. http://dx.doi.org/10.1080/0169096 9308407585

Hutzler, F., Braun, M., Võ, M. L-H., Engl, V., Hofmann, M., Dambacher, M., . . Jacobs, A. M. (2007). Welcome to the real world: Validating fixationrelated brain potentials for ecologically valid settings. Brain Research, 1172, 124-129. http://dx.doi.org/10.1016/j.brainres.2007.07.025

Jackendoff, R. (2007). A Parallel architecture perspective on language processing. Brain Research, 1146, 2-22. http://dx.doi.org/10.1016/j.brainres .2006.08.111

Jackson, M. D., \& McClelland, J. L. (1975). Sensory and cognitive determinants of reading speed. Journal of Verbal Learning \& Verbal Behavior, 14, 565-574. http://dx.doi.org/10.1016/S0022-5371(75)80044-2

Jaeger, T. F. (2008). Categorical data analysis: Away from ANOVAs (transformation or not) and towards logit mixed models. Journal of Memory and Language, 59, 434-446. http://dx.doi.org/10.1016/j.jml.2007.11.007

Jung, T. P., Makeig, S., Humphries, C., Lee, T. W., McKeown, M. J., Iragui, V., \& Sejnowski, T. J. (2000). Removing electroencephalographic artifacts by blind source separation. International Journal of Psychophysiology, 37, 163-178. http://dx.doi.org/10.1111/1469-8986.3720163

Kaan, E. (2009). Fundamental syntactic phenomena and their putative relation to the brain. In D. Bickerton \& E. Szathmáry (Eds.), Biological foundations and origin of syntax (Vol. 3, pp. 117-134). Cambridge, MA: MIT Press.

Kaan, E., Harris, A., Gibson, E., \& Holcomb, P. (2000). The P600 as an index of syntactic integration difficulty. Language and Cognitive Processes, 15, 159-201. http://dx.doi.org/10.1080/016909600386084

Kornrumpf, B., Niefind, F., Sommer, W., \& Dimigen, O. (2016). Neural correlates of word recognition: A systematic comparison of natural reading and rapid serial visual presentation. Journal of Cognitive Neuroscience, 28, 1374-1391. http://dx.doi.org/10.1162/jocn_a_00977

Kuperberg, G. R. (2007). Neural mechanisms of language comprehension: Challenges to syntax. Brain Research, 1146, 23-49. http://dx.doi.org/ 10.1016/j.brainres.2006.12.063

Kutas, M., \& Federmeier, K. D. (2011). Thirty years and counting: Finding meaning in the N400 component of the event-related brain potential (ERP). Annual Review of Psychology, 62, 621-647. http://dx.doi.org/10 .1146/annurev.psych.093008.131123

Kutas, M., \& Hillyard, S. A. (1980). Reading senseless sentences: Brain potentials reflect semantic incongruity. Science, 207, 203-205. http://dx .doi.org/10.1126/science.7350657

Kutas, M., Van Petten, C. K., \& Kluender, R. (2006). Psycholinguistics Electrified II (1994-2005). In M. J. Traxler \& M. A. Gernsbacher (Eds.), Handbook of psycholinguistics (pp. 659-724). San Diego, CA: Academic Press. http://dx.doi.org/10.1016/B978-012369374-7/50018-3

Lau, E. F., Phillips, C., \& Poeppel, D. (2008). A cortical network for semantics: (de)constructing the N400. Nature Reviews Neuroscience, 9, 920-933. http://dx.doi.org/10.1038/nrn2532

Li, N., Niefind, F., Wang, S., Sommer, W., \& Dimigen, O. (2015). Parafoveal processing in reading Chinese sentences: Evidence from event-related brain potentials. Psychophysiology, 52, 1361-1374. http:// dx.doi.org/10.1111/psyp. 12502

Lopez-Calderon, J., \& Luck, S. J. (2014). ERPLAB: An open-source toolbox for the analysis of event-related potentials. Frontiers in Human Neuroscience, 8, 213. http://dx.doi.org/10.3389/fnhum.2014.00213

López-Peréz, P. J., Dampuré, J., Hernández-Cabrera, J. A., \& Barber, H. A. (2016). Semantic parafoveal-on-foveal effects and preview benefits in reading: Evidence from Fixation Related Potentials. Brain and Language, 162, 29-34. http://dx.doi.org/10.1016/j.bandl.2016.07.009

Maris, E., \& Oostenveld, R. (2007). Nonparametric statistical testing of EEG- and MEG-data. Journal of Neuroscience Methods, 164, 177-190. http://dx.doi.org/10.1016/j.jneumeth.2007.03.024

Marslen-Wilson, W., \& Tyler, L. K. (1975). Processing structure of sentence perception. Nature, 257, 784-786. http://dx.doi.org/10 $1038 / 257784 \mathrm{aO}$

Marslen-Wilson, W., \& Tyler, L. K. (1980). The temporal structure of spoken language understanding. Cognition, 8, 1-71. http://dx.doi.org/10 .1016/0010-0277(80)90015-3

Mathôt, S., Schreij, D., \& Theeuwes, J. (2012). OpenSesame: An opensource, graphical experiment builder for the social sciences. Behavior Research Methods, 44, 314-324. http://dx.doi.org/10.3758/s13428-0110168-7

Metting van Rijn, A. C., Peper, A., \& Grimbergen, C. A. (1990). Highquality recording of bioelectric events. Part 1 . Interference reduction, theory and practice. Medical \& Biological Engineering \& Computing, 28, 389-397. http://dx.doi.org/10.1007/BF02441961

Metzner, P., von der Malsburg, T., Vasishth, S., \& Rösler, F. (2015). Brain responses to world knowledge violations: A comparison of stimulus- and fixation-triggered event-related potentials and neural oscillations. Journal of Cognitive Neuroscience, 27, 1017-1028. http://dx.doi.org/10 .1162/jocn_a_00731

Mirault, J., Yeaton, J., Broqua, F., Dufau, S., Holcomb, P., \& Grainger, J. (2019). Parafoveal-on-foveal repetition effects in sentence reading: A co-registered eye-tracking and EEG study. Manuscript under review.

Mirault, J., Snell, J., \& Grainger, J. (2018). You that read wrong again! A transposed-word effect in grammaticality judgments. Psychological Science, 29. http://dx.doi.org/10.1177/0956797618806296

Molinaro, N., Barber, H. A., \& Carreiras, M. (2011). Grammatical agreement processing in reading: ERP findings and future directions. Cortex 47, 908-930. http://dx.doi.org/10.1016/j.cortex.2011.02.019

Nikolaev, A. R., Meghanathan, R. N., \& van Leeuwen, C. (2016). Combining EEG and eye movement recording in free viewing: Pitfalls and 
possibilities. Brain and Cognition, 107, 55-83. http://dx.doi.org/10 .1016/j.bandc.2016.06.004

Oostenveld, R., Fries, P., Maris, E., \& Schoffelen, J. M. (2011). FieldTrip: Open source software for advanced analysis of MEG, EEG, and invasive electrophysiological data. Computational Intelligence and Neuroscience, 2011, 156869. http://dx.doi.org/10.1155/2011/156869

Osterhout, L. (1997). On the brain response to syntactic anomalies: Manipulations of word position and word class reveal individual differences. Brain and Language, 59, 494-522. http://dx.doi.org/10.1006/brln .1997 .1793

Osterhout, L., \& Holcomb, P. (1992). Event-related brain potentials elicited by syntactic anomaly. Journal of Memory and Language, 31, 785-806. http://dx.doi.org/10.1016/0749-596X(92)90039-Z

Osterhout, L., McLaughlin, J., Kim, A., Greenwald, R., \& Inoue, K. (2004). Sentences in the brain: Event-related potentials as real-time reflections of sentence comprehension and language learning. In M. Carreiras \& J. Clifton (Eds.), The on-line study of sentence comprehension: Eyetracking, ERP, and beyond (pp. 271-308). London, UK: Psychology Press.

Osterhout, L., \& Mobley, L. A. (1995). Event-related brain potentials elicited by failure to agree. Journal of Memory and Language, 34, 739-773. http://dx.doi.org/10.1006/jmla.1995.1033

Osterhout, L., \& Nicol, J. (1999). On the distinctiveness, independence, and time course of the brain responses to syntactic and semantic anomalies. Language and Cognitive Processes, 14, 283-317. http://dx.doi .org/10.1080/016909699386310

Payne, B. R., \& Federmeier, K. D. (2017). Pace yourself: Intraindividual variability in context use revealed by self-paced event-related brain potentials. Journal of Cognitive Neuroscience, 29, 837-854. http://dx .doi.org/10.1162/jocn_a 01090

Pegado, F., \& Grainger, J. (2019). A transposed-word effect in samedifferent judgments to sequences of words. Journal of Experimental Psychology: Learning, Memory, and Cognition. Advance online publication. http://dx.doi.org/10.1037/xlm0000776

Peirce, J. W. (2009). Generating stimuli for neuroscience using PsychoPy. Frontiers in Neuroinformatics, 2, 10. http://dx.doi.org/10.3389/neuro.11 .010 .2008

$\mathrm{R}$ Core Team. (2017). R: A language and environment for statistical computing. Vienna, Austria: R Foundation for Statistical Computing.

Reichle, E. D., Liversedge, S. P., Pollatsek, A., \& Rayner, K. (2009). Encoding multiple words simultaneously in reading is implausible. Trends in Cognitive Sciences, 13, 115-119. http://dx.doi.org/10.1016/j tics.2008.12.002

Sanford, A. J. (2002). Context, attention and depth of processing during interpretation. Mind \& Language, 17, 188-206. http://dx.doi.org/10 1111/1468-0017.00195

Schotter, E. R., \& Payne, B. R. (2019). Eye movements and comprehension are important to reading. Trends in Cognitive Sciences, 23, 811-812. http://dx.doi.org/10.1016/j.tics.2019.06.005

Schotter, E. R., Reichle, E. D., \& Rayner, K. (2014). Rethinking parafoveal processing in reading: Serial-attention models can explain semantic preview benefit and N+2 preview effects. Visual Cognition, 22, 309333. http://dx.doi.org/10.1080/13506285.2013.873508

Schutter, D. J. L. G., Leitner, C., Kenemans, J. L., \& van Honk, J. (2006). Electrophysiological correlates of cortico-subcortical interaction: A cross-frequency spectral EEG analysis. Clinical Neurophysiology, 117, 381-387. http://dx.doi.org/10.1016/j.clinph.2005.09.021

Snell, J., Declerck, M., \& Grainger, J. (2018). Parallel semantic processing in reading revisited: Effects of translation equivalents in bilingual readers. Language, Cognition and Neuroscience, 33, 563-574. http://dx.doi .org/10.1080/23273798.2017.1392583

Snell, J., \& Grainger, J. (2017). The sentence superiority effect revisited. Cognition, 168, 217-221. http://dx.doi.org/10.1016/j.cognition.2017.07 .003
Snell, J., \& Grainger, J. (2019a). Readers are parallel processors. Trends in Cognitive Sciences, 23, 537-546. http://dx.doi.org/10.1016/j.tics.2019 .04 .006

Snell, J., \& Grainger, J. (2019b). Word position coding in reading is noisy. Psychonomic Bulletin \& Review, 26, 609-615. http://dx.doi.org/10 .3758/s13423-019-01574-0

Snell, J., Meade, G., Meeter, M., Holcomb, P., \& Grainger, J. (2019). An electrophysiological investigation of orthographic spatial integration in reading. Neuropsychologia, 129, 276-283. http://dx.doi.org/10.1016/j .neuropsychologia.2019.04.009

Snell, J., Meeter, M., \& Grainger, J. (2017). Evidence for simultaneous syntactic processing of multiple words during reading. PLOS ONE, 12, e0173720. http://dx.doi.org/10.1371/journal.pone.0173720

Stites, M. C., Payne, B. R., \& Federmeier, K. D. (2017). Getting ahead of yourself: Parafoveal word expectancy modulates the N400 during sentence reading. Cognitive, Affective \& Behavioral Neuroscience, 17, 475-490. http://dx.doi.org/10.3758/s13415-016-0492-6

Stowe, L. A., Kaan, E., Sabourin, L., \& Taylor, R. C. (2018). The sentence wrap-up dogma. Cognition, 176, 232-247. http://dx.doi.org/10.1016/j .cognition.2018.03.011

Swaab, T. Y., Ledoux, K., Camblin, C. C., \& Boudewyn, M. A. (2012) Language-related ERP components. In E. S. Kappenman \& S. J. Luck (Eds.), The Oxford handbook of event-related potential components (pp. 397-439). New York, NY: Oxford University Press.

Tanner, D. (2015). On the left anterior negativity (LAN) in electrophysiological studies of morphosyntactic agreement: A commentary on "grammatical agreement processing in reading: ERP findings and future directions" by Molinaro et al. (2014). Cortex, 66, 149-155. http://dx.doi org/10.1016/j.cortex.2014.04.007

Tanner, D. (2019). Robust neurocognitive individual differences in grammatical agreement processing: A latent variable approach. Cortex, 111, 210-237. http://dx.doi.org/10.1016/j.cortex.2018.10.011

Tanner, D., \& Van Hell, J. G. (2014). ERPs reveal individual differences in morphosyntactic processing. Neuropsychologia, 56, 289-301. http:// dx.doi.org/10.1016/j.neuropsychologia.2014.02.002

Thierry, G., \& Wu, Y. J. (2007). Brain potentials reveal unconscious translation during foreign-language comprehension. Proceedings of the National Academy of Sciences of the United States of America, 104, 12530-12535. http://dx.doi.org/10.1073/pnas.0609927104

Townsend, D. J., \& Bever, T. G. (2001). Sentence comprehension: The integration of habits and rules. Cambridge, MA: MIT Press.

Ueno, M., \& Kluender, R. (2003). Event-related brain indices of Japanese scrambling. Brain and Language, 86, 243-271. http://dx.doi.org/10.1016/ S0093-934X(02)00543-6

van Herten, M., Chwilla, D. J., \& Kolk, H. H. J. (2006). When heuristics clash with parsing routines: ERP evidence for conflict monitoring in sentence perception. Journal of Cognitive Neuroscience, 18, 1181-1197. http://dx.doi.org/10.1162/jocn.2006.18.7.1181

van Heuven, W. J. B., Mandera, P., Keuleers, E., \& Brysbaert, M. (2014). SUBTLEX-U. K.: A new and improved word frequency database for British English. Quarterly Journal of Experimental Psychology: Human Experimental Psychology, 67, 1176-1190. http://dx.doi.org/10.1080/ 17470218.2013.850521

Vergara-Martínez, M., Perea, M., Gómez, P., \& Swaab, T. Y. (2013). ERP correlates of letter identity and letter position are modulated by lexical frequency. Brain and Language, 125, 11-27. http://dx.doi.org/10.1016/ j.bandl.2012.12.009

Wen, Y., Filik, R., \& van Heuven, W. J. B. (2018). Electrophysiological dynamics of Chinese phonology during visual word recognition in Chinese-English bilinguals. Scientific Reports, 8, 6869. http://dx.doi.org/ 10.1038/s41598-018-25072-w

Wen, Y., Snell, J., \& Grainger, J. (2019). Parallel, cascaded, interactive processing of words during sentence reading. Cognition, 189, 221-226. http://dx.doi.org/10.1016/j.cognition.2019.04.013 
White, A. L., Boynton, G. M., \& Yeatman, J. D. (2019). You can't recognize two words simultaneously. Trends in Cognitive Sciences, 23, 812-814. http://dx.doi.org/10.1016/j.tics.2019.07.001

Zhang, W., Li, N., Wang, X., \& Wang, S. (2015). Integration of sentencelevel semantic information in parafovea: Evidence from the RSVPflanker paradigm. PLoS ONE, 10, e0139016. http://dx.doi.org/10.1371/ journal.pone.0139016

Zhang, W., Zhen, A., Liang, B., \& Mo, L. (2019). The parallel mechanism of semantic context influences and parafoveal word identification. $\mathrm{Neu}$ roscience Letters, 704, 73-77. http://dx.doi.org/10.1016/j.neulet.2019 .03 .026
Received June 5, 2019

Revision received October 15, 2019 Accepted December 4, 2019

\section{P AMERICAN PSYCHOLOGICAL ASSOCIATION}

\section{APA Journals}

\section{ORDER INFORMATION}

Subscribe to This Journal for 2021

Order Online:

Visit at.apa.org/xIm-2021

for pricing and access information.

Call 800-374-2721 or 202-336-5600

Fax 202-336-5568 | TDD/TTY 202-336-6123

Subscription orders must be prepaid. Subscriptions are on a calendar year basis. Please allow 4-6 weeks for delivery of the first issue.

All APA journal subscriptions include Online First journal articles and access to archives. Individuals can receive online access to all of APA's scholarly journals through a subscription to APA PsycNet ${ }^{\circ}$ or through an institutional subscription to the APA PsycArticles ${ }^{\circ}$ database

Visit AT.APA.ORG/CIRC2021

to browse APA's full journal collection 